\title{
Color Doppler Tissue Imaging in Assessing the Elastic Properties of the Aorta and in Predicting Coronary Artery Disease
}

\author{
Namik Kemal ERYOL, ${ }^{1}$ MD, Ramazan TOPSAKAL,${ }^{1} \mathrm{MD}$, Yüksel Çıç EK, ${ }^{1} \mathrm{MD}$, \\ Adnan ABACI, ${ }^{1} \mathrm{MD}$, Abdurahman OGUZHAN, ${ }^{1} \mathrm{MD}$, \\ Emrullah BASAR, ${ }^{1} \mathrm{MD}$, and Ali ERGIN, ${ }^{1} \mathrm{MD}$
}

\section{SUMMARY}

We hypothesized that the change in aortic elastic properties could directly be shown with color Doppler tissue imaging (CDTI), that these findings could be related to aortic stiffness and distensibility and that, through these, coronary artery disease (CAD) could be predicted.

One hundred and twenty six patients (group I: 83 with CAD, mean age $54 \pm 10$ years,

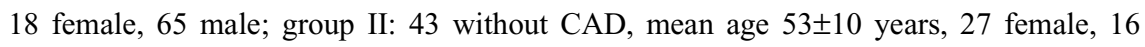
male) having been evaluated for coronary artery disease by angiography were examined by echocardiography. Arterial pressure was measured immediately before echocardiographic evaluation. Internal aortic systolic and diastolic diameters by M-mode echocardiography and aortic upper wall tissue velocities (Aortic S, E, A, m/sec) by CDTI were measured $3 \mathrm{~cm}$ above the aortic valve. Lateral mitral annulus tissue velocities (Annulus $\mathrm{S}, \mathrm{E}, \mathrm{A}, \mathrm{m} / \mathrm{sec})$ were also recorded. Aortic distensibility $\left(\mathrm{cm}^{2} \bullet \mathrm{dynes}^{-1}\right)$ and aortic stiffness index were calculated using formulas. In the statistical analyses, CAD risk factors and left ventricular ejection fraction were used for adjustment.

Aortic stiffness $(2.79 \pm 3.49$ vs $1.62 \pm 1.31, P=0.03)$, distensibility $(1.55 \pm 1.46$ vs $2.37 \pm 3.08, P=0.04)$, and aortic $\mathrm{S}$ velocity $(0.057 \pm 0.016$ vs $0.064 \pm 0.015, P=0.02)$ differed significantly between groups I and II. After adjustment, while aortic stiffness and $\mathrm{S}$ velocity were still statistically different ( $P=0.04 ; P=0.03$ respectively), the significance of the difference in aortic distensibility disappeared $(P=0.051)$. Aortic stiffness and aortic $\mathrm{S}$ velocity $(0.06 \mathrm{~m} / \mathrm{sec}<$ ) were important $\mathrm{CAD}$ determinants (Odds ratio=1.4 $P=0.03$; Odds ratio=3.6 $P=0.01$, respectively), but aortic distensibility was not. Aortic stiffness was correlated only with aortic $\mathrm{S}$ velocity $(r=-0.28, P=0.01)$, and aortic distensibility had a significantly positive correlation with aortic $\mathrm{S}$ velocity $(r=0.20, P=0.02)$. The interobserver and intraobserver correlation coefficients for aortic $\mathrm{S}$ velocities were 0.65 and 0.71 , respectively $(P<0.05)$.

Elastic properties of the aorta can directly be assessed by reproducibly measuring the movements in the upper wall of the aorta by CDTI. Reduced aortic S velocity is associ-

From the ${ }^{1}$ Department of Cardiology, Erciyes University Medical School, Kayseri, Turkey.

Address for correspondence: Nam Kemal Eryol, MD, Serceonu mah. Cankaya cad. 13/7, 38010, Kayseri, Turkey.

Received for publication November 19, 2001.

Revised and accepted February 22, 2002. 
ated with increased aortic stiffness. Increased aortic stiffness and reduced aortic $\mathrm{S}$ velocity are important predictors of CAD. (Jpn Heart J 2002; 43: 219-230)

Key words: Color Doppler tissue imaging, Aortic stiffness, CAD

THE aorta has an elastic structure, and it is generally affected by arteriosclerosis. The changes in elastic structure caused by arteriosclerosis are reflected by an increase in aortic stiffness and a decrease in distensibility. ${ }^{1,2)}$ Since arteriosclerosis may affect the aorta and coronary arteries simultaneously, ${ }^{3}$ it has been shown that aortic stiffness and distensibility may be markers of coronary events. ${ }^{4,5)}$ It is inevitable that the arterial pulse is affected by the changes in aortic stiffness and distensibility. It was for this reason that the velocity of transmission of the pulse wave was used as a clinical index of arterial elasticity by Bramwell and Hill in $1922,{ }^{6}$ ) and then by a large number of authors using different methods. ${ }^{7-9)}$ Today, calculation of pulse wave velocity ${ }^{10)}$ and aortic stiffness index ${ }^{11)}$ are commonly being used as noninvasive methods. These methods are not without drawbacks since they are indirect to a certain extent. However, recent developments in echocardiography have provided the opportunity to evaluate the movements of tissues directly. A new third-generation color Doppler tissue image (CDTI) system with improved spatial and temporal resolution has been developed that allows real-time acquisition of color Doppler images with subsequent off-line computer analysis of regional mean velocities. With this system, it has become possible to record Doppler signals of low speed but high amplitude caused by the movement of the myocardium. ${ }^{12,13)}$ During ventricular systole and diastole, arterial wall movements which cause a differentiation in the diameter of the proximal aortic lumen also occur. If these wall movements can be recorded reproducibly by CDTI, it will be possible to form an opinion about the changes in the elastic structure of the aorta.

The purpose of this study was to investigate the possibility of reproducible measurements of the wall movements in the proximal aorta by CDTI, the correlation between the aortic stiffness index, distensibility, and CDTI measurements, and finally, the possibility of predictions of CDTI measurements, aortic stiffness index, and distensibility on coronary artery disease (CAD).

\section{Materials ANd Methods}

Subjects: The study population consisted of 126 patients (45 males and 81 females) who were subjected to coronary angiography due to their symptoms and clinical findings suggestive of CAD. Patients with valvular disease, congenital 
heart disease, cardiomyopathy or atrial fibrillation, and those without sufficient echocardiographic images were excluded from the study. Patients with at least a critical or noncritical coronary artery lesion were classified as the patients with CAD (83 patients, 18 females, 65 males mean age $55 \pm 10$ years). Patients who had no coronary lesions were classified as the patients without CAD (43 patients, 27 females, 16 males mean age $54 \pm 10$ years). Both groups were investigated for hypertension, diabetes mellitus, smoking habit, and hyperlipidemia.

Echocardiography: Echocardiographic examinations were conducted using a $2.5 \mathrm{mHz}$ probe with a Wingmed system- 5 echocardiography device by two cardiologists blinded to the coronary angiography results. Pulse rates and blood pressures were measured immediately before echocardiographic evaluation. Left ventricular ejection fraction (LVEF) was measured using the Teichholz formula, and the Simpson method when necessary. The systolic and diastolic diameters of the aorta were measured between the lower edge of the upper wall and the upper edge of the lower wall $3 \mathrm{~cm}$ above the aortic valve using M-mode echocardiography in a parasternal long axis view. The aortic systolic diameter (AoS) was measured while the aortic valve was completely open, and the aortic diastolic diameter (AoD) was measured at a point corresponding to the peak of QRS in ECG (Figure 1). The systolic and diastolic indices of the aorta were calculated by

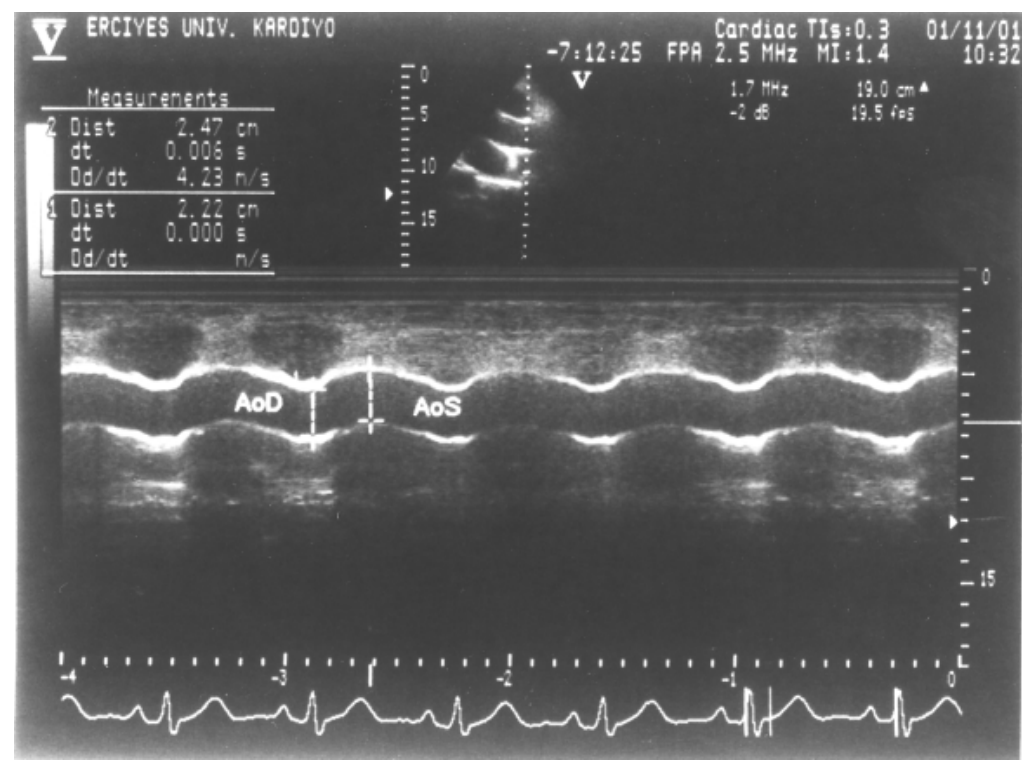

Figure 1. Systolic and diastolic diameter measurements of the aorta with M-mode echocardiography. 
dividing AoS and AoD by the body surface area. Then, by switching into the tissue Doppler echocardiography mode, aortic upper wall velocity (Aortic S, E, A velocity $\mathrm{m} / \mathrm{sec}$ ) was measured at the same point as in the M-mode measurements. Unlike aortic $\mathrm{E}$ and $\mathrm{A}$ velocities, $\mathrm{S}$ velocity had a positive profile, indicating that the aorta expands towards the cursor during ventricular systole (Figure 2). Lateral mitral annulus velocities were measured on the apical four chamber view. All CDTI measurements were made in 5 consecutive cycles and averaged.

Calculation of aortic distensibility and stiffness: Aortic root distensibility and stiffness were calculated using the following formulae. ${ }^{11)}$ Aortic root distensibility $=2 \times($ AoS-AoD) / PP x AoD; Aortic stiffness index $=\ln ($ SBP/DBP) / (AoSAoD) / AoD, where PP stands for pulse pressure, SBP systolic blood pressure, and DBP diastolic blood pressure.

IBM compatible SPSS (version 10.0) for statistical analysis, and NCSS statistical program for plotting were used. Interobserver variability and intraobserver variability were tested by the Spearmen rank correlation coefficient. The differences between the measurements were tested using the two-tailed Student's $t$ test and 'general Linear model-general factorial test', and a prediction was tested by logistic regression analysis. The correlations were tested using the Spearman correlation coefficient and linear regression analyses. A cut-off value of $0.06 \mathrm{~m} / \mathrm{sec}$ for $\mathrm{S}$ velocity in the upper wall of the aorta was detected by ROC analysis (sensitivity: $72 \%$, specificity:53.5\%), and values less than $0.06 \mathrm{~m} / \mathrm{sec}$

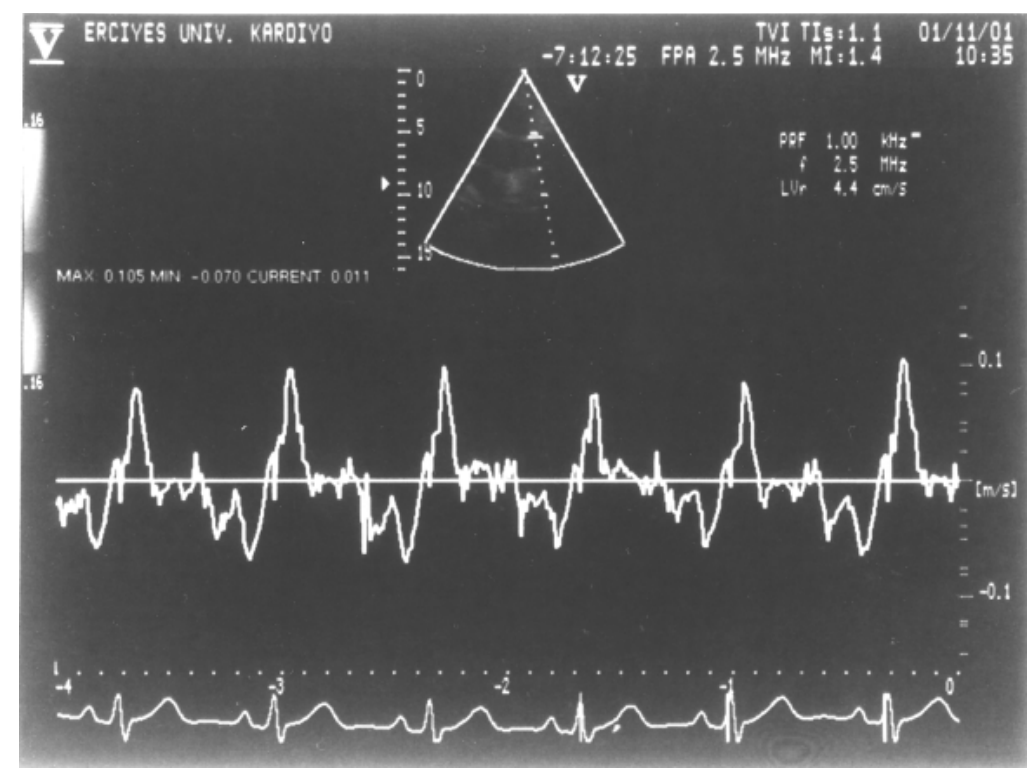

Figure 2. Aortic upper wall velocity measurements with color Doppler tissue imaging. 
were accepted as decreased aortic S velocity. Age, sex, hypertension, diabetes mellitus, smoking habit, total cholesterol level, triglycerides level, HDL-cholesterol level, and LVEF measurements were used as covariants. $P<0.05$ was taken as statistically significant.

\section{RESUlts}

The clinical characteristics of the patients with and without CAD are presented in Table I. Gender, body surface area, the number of patients with hypertension and a smoking habit, aortic diastolic diameter, and left ventricle ejection fraction differed significantly between the two groups $(P<0.05)$.

The values of aortic stiffness, aortic distensibility, and color Doppler tissue imaging measurements were compared between patients with and without CAD (Table II). The aortic stiffness index was significantly higher $(2.79 \pm 3.49$ vs $1.62 \pm 1.31, P=0.037$ ) (Figure 3 ) and aortic distensibility was significantly lower $\left(1.55 \pm 1.46\right.$ vs $2.37 \pm 3.08 \mathrm{~cm}^{2} \bullet$ dynes $\left.^{-1}, P=0.04\right)$ in patients with CAD than in those without $\mathrm{CAD}$. Aortic $\mathrm{S}$ velocity was also significantly lower in patients with $\mathrm{CAD}(0.0570 \pm 0.016$ vs $0.064 \pm 0.015 \mathrm{~m} / \mathrm{sec}, P=0.02)$, (Figure 4$)$. However, a per-

Table I. Clinical Characteristics of Patients with and without CAD

\begin{tabular}{lccc}
\hline & $\begin{array}{c}\text { With CAD } \\
n=83\end{array}$ & $\begin{array}{c}\text { Without CAD } \\
n=43\end{array}$ & $P$ \\
& & & \\
\hline Age (years) & $54 \pm 10$ & $53 \pm 10$ & 0.05 \\
Sex Male (\%) & 78 & 37 & 0.01 \\
$\quad$ Female (\%) & 22 & 63 & \\
Hypertension (\%) & 35 & 56 & 0.02 \\
Diabetes mellitus $(\%)$ & 22 & 16 & $>0.05$ \\
Smoking habit $(\%)$ & 51 & 30 & 0.02 \\
Body surface area (m $\left.{ }^{2}\right)$ & $1.84 \pm 0.01$ & $1.77 \pm 0.02$ & 0.01 \\
Total cholesterol $(\mathrm{mg} / \mathrm{dL})$ & $199 \pm 38$ & $193 \pm 39$ & $>0.05$ \\
HDL-cholesterol $(\mathrm{mg} / \mathrm{dL})$ & $40 \pm 7$ & $40 \pm 11$ & $>0.05$ \\
Triglycerides $(\mathrm{mg} / \mathrm{dL})$ & $195 \pm 101$ & $181 \pm 112$ & $>0.05$ \\
Systolic blood pressure $(\mathrm{mm} / \mathrm{Hg})$ & $133 \pm 23$ & $132 \pm 18$ & $>0.05$ \\
Diastolic blood pressure $(\mathrm{mm} / \mathrm{Hg})$ & $71 \pm 13$ & $73 \pm 13$ & $>0.05$ \\
Pulse pressure $(\mathrm{mm} / \mathrm{Hg})$ & $62 \pm 2$ & $59 \pm 13$ & $>0.05$ \\
Aortic systolic diameter $(\mathrm{cm})$ & $3.12 \pm 0.03$ & $3.01 \pm 0.03$ & $>0.05$ \\
Aortic diastolic diameter $(\mathrm{cm})$ & $2.96 \pm 0.03$ & $2.80 \pm 0.03$ & 0.01 \\
Aortic systolic index $\left(\mathrm{cm} / \mathrm{m}^{2}\right)$ & $1.70 \pm 0.02$ & $1.70 \pm 0.01$ & $>0.05$ \\
Aortic diastolic index $\left(\mathrm{cm} / \mathrm{m}^{2}\right)$ & $1.61 \pm 0.02$ & $1.58 \pm 0.02$ & $>0.05$ \\
Left ventricle ejection fraction $(\%)$ & $60 \pm 10$ & $65 \pm 8$ & 0.01 \\
\hline CAD & & & \\
\hline
\end{tabular}

$\mathrm{CAD}=$ coronary artery disease. 
Table II. Aortic Stiffness, Aortic Distensibility and Color Doppler Tissue Imaging Measurements in Patients with and without CAD

\begin{tabular}{lccc}
\hline & With CAD & Without CAD & $P$ \\
\hline Aortic stiffness index & $2.79 \pm 3.49$ & $1.62 \pm 1.31$ & 0.037 \\
Aortic distensibility $\left(\mathrm{cm}^{2}\right.$ dynes $\left.^{-1}\right)$ & $1.55 \pm 1.46$ & $2.37 \pm 3.08$ & $0.044^{*}$ \\
Aortic upper wall S velocity $(\mathrm{m} / \mathrm{sec})$ & $0.057 \pm 0.016$ & $0.064 \pm 0.015$ & 0.023 \\
Aortic upper wall E velocity $(\mathrm{m} / \mathrm{sec})$ & $0.049 \pm 0.020$ & $0.054 \pm 0.019$ & $>0.05$ \\
Aortic upper wall A velocity $(\mathrm{m} / \mathrm{sec})$ & $0.069 \pm 0.019$ & $0.075 \pm 0.020$ & $>0.05$ \\
Mitral lateral annulus S velocity $(\mathrm{m} / \mathrm{sec})$ & $0.077 \pm 0.095$ & $0.071 \pm 0.029$ & $>0.05$ \\
Mitral lateral annulus E velocity $(\mathrm{m} / \mathrm{sec})$ & $0.073 \pm 0.030$ & $0.077 \pm 0.024$ & $>0.05$ \\
Mitral lateral annulus A velocity $(\mathrm{m} / \mathrm{sec})$ & $0.074 \pm 0.028$ & $0.077 \pm 0.031$ & $>0.05$ \\
\hline
\end{tabular}

*, significance disappeared after adjustment; $\mathrm{CAD}=$ coronary artery disease.

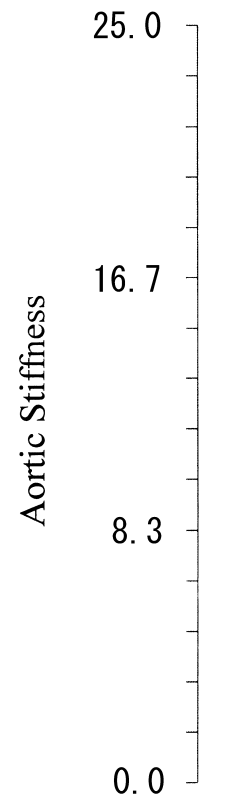

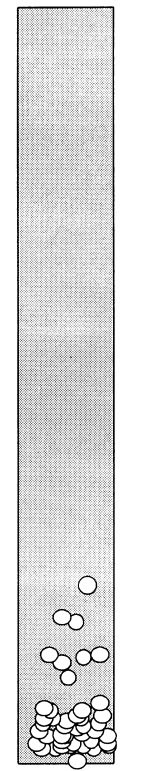

Without CAD

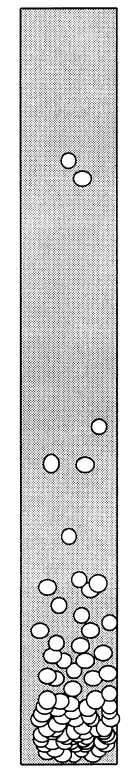

With CAD

Figure 3. Comparison of the aortic stiffness values in patients with and without CAD represented graphically. $(P=0.037 ; \mathrm{CAD}=$ coronary artery disease $)$ 


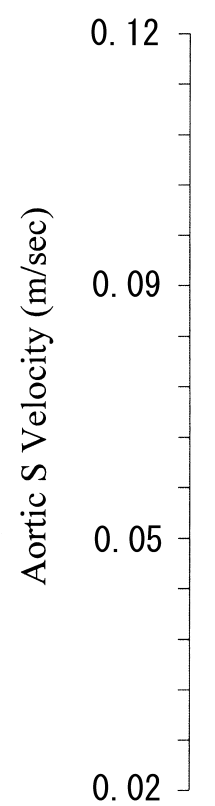

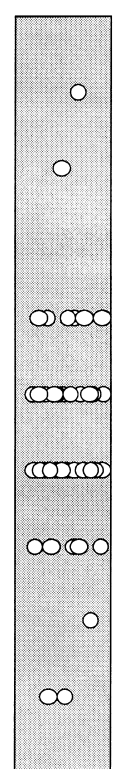

Without CAD

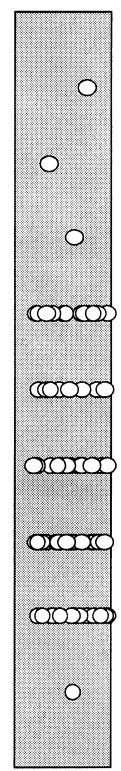

With CAD

Figure 4. Comparison of aortic upper wall $\mathrm{S}$ velocity values in patients with and without CAD represented graphically. $P=0.023 ; \mathrm{CAD}=$ coronary artery disease.

sistent difference between the groups was observed only in aortic stiffness index and the aortic $\mathrm{S}$ velocity after adjustments for covariates $(P=0.04, P=0.03)$.

In analyses testing the reproducibility of aortic $S$ velocity, the interobserver and intraobserver correlation coefficients for the aortic $\mathrm{S}$ velocities were 0.65 and 0.71 in CDTI, respectively $(P=0.04, P=0.04)$.

The odds ratios of the aortic stiffness index and aortic $\mathrm{S}$ velocity in predicting coronary artery disease were calculated (Table III). Decreased aortic S velocity and the aortic stiffness index were predictive of CAD (Odds ratio=3.6, $P=0.01 ; 1.4, P=0.03$, respectively).

The relationships between aortic stiffness and aortic distensibility to the color Doppler tissue imaging measurements were tested (Table IV). The aortic stiffness index was negatively correlated only with aortic S velocity in the CDTI measurements $(r=-0.28, P=0.01)$. Aortic distensibility, on the other hand, was positively correlated with aortic $\mathrm{S}$ velocity $(r=0.20, P=0.02)$, aortic E velocity $(r=0.22, P=0.01)$, and annulus E velocity $(r=0.21, P=0.01)$, and negatively with 
Table III. Odds Ratios in the Prediction of Coronary Artery Disease, Aortic Stiffness Index, and Aortic Upper Wall S Velocity

\begin{tabular}{lllcl}
\hline & Odds ratio & \multicolumn{2}{l}{$95 \%$ confidence interval } & $P$ \\
\hline Aortic stiffness index & 1.40 & 1.03 & 1.91 & 0.03 \\
Aortic upper wall S velocity $(\mathrm{m} / \mathrm{sec})$ & 3.68 & 1.28 & 10.57 & 0.01 \\
\hline
\end{tabular}

Table IV. Relationships between Color Doppler Tissue Imaging Measurements and Aortic Stiffness and Aortic Distensibility

\begin{tabular}{lcccc}
\hline & \multicolumn{2}{c}{ Aortic stiffness index } & \multicolumn{2}{c}{ Aortic distensibility } \\
& $r$ & $P$ & $r$ & $P$ \\
\hline Aortic upper wall S velocity $(\mathrm{m} / \mathrm{sec})$ & -0.28 & 0.01 & 0.20 & 0.02 \\
Aortic upper wall E velocity $(\mathrm{m} / \mathrm{sec})$ & -0.11 & $>0.05$ & 0.22 & 0.01 \\
Aortic upper wall A velocity $(\mathrm{m} / \mathrm{sec})$ & 0.01 & $>0.05$ & 0.97 & $>0.05$ \\
Mitral lateral annulus S velocity $(\mathrm{m} / \mathrm{sec})$ & 0.11 & $>0.05$ & -0.12 & $>0.05$ \\
Mitral lateral annulus E velocity $(\mathrm{m} / \mathrm{sec})$ & -0.17 & $>0.05$ & 0.21 & 0.01 \\
Mitral lateral annulus A velocity $(\mathrm{m} / \mathrm{sec})$ & 0.04 & $>0.05$ & -0.22 & 0.01 \\
\hline
\end{tabular}

annulus A velocity $(r=-0.22, P=0.01)$. Of the CDTI measurements on the mitral lateral annulus and the aortic upper wall, there was a correlation only between $\mathrm{E}$ and A velocities ( $r=0.21, r=0.41, P=0.02, P=0.01$, respectively).

\section{DISCUSSION}

The changesin the elastic properties of the aorta are associated with CAD. ${ }^{3-5)}$ It has been demonstrated that increased aortic stiffness and decreased distensibility, which indicate impairment in the elastic structure of the aorta, are associated with CAD and CAD risk factors. ${ }^{11,14-18)}$ Therefore, there should be some clinical benefits in detecting, using a practical method, the changes likely to occur in aortic stiffness and distensibility. Aortic stiffness and distensibility have so far been studied frequently with different methods which used arterial pulse properties. $^{6-9)}$ The arterial pulse is a fluctuation caused by heart contraction and occurs at the same frequency as the heart rate. The ejection of blood from the left ventricle through the aortic valve in the aorta leads to flow, pressure, and diameter pulsations (waves), and these pulsations propagate throughout the arterial tree at a speed determined by the elastic and geometric properties of the arterial wall and the characteristics (density) of the contained fluid (blood). ${ }^{19)}$

The measurement of pulse (pressure and flow) wave velocity (PWV) is one that has been widely employed for a long time to evaluate arterial wall distensi- 
bility and stiffness. ${ }^{69)}$ The velocity with which the pulse wave is transmitted is dependent primarily on the coefficient of elasticity or rigidity of the artery. However, many factors deserve consideration. Some of these factors are related to hematological and cardiovascular physiology such as viscosity, gender, ${ }^{20)}$ age ${ }^{20)}$ salt intake, ${ }^{21)}$ meals, ${ }^{22}$ blood flow, ${ }^{23)}$ respiration, ${ }^{24)}$ and others are consecutive with pathophysiological conditions such as hypertension, ${ }^{25)}$ diabetes, ${ }^{26)}$ dyslipidemia, ${ }^{27)}$ arteriosclerosis, and coronary artery disease. ${ }^{28)}$ Hence, the effects of these conditions on PWV will be inevitable, which presents itself as a major disadvantage.

Similarly in formulaic AS index computation, another method, there are also shortcomings. The parameters used in formulae are the changes in the diameter during systole and diastole, and PP. With increasing age, hypertension, and arterio- and atherosclerosis, the arterial wall thickness increases and presents functional and structural abnormalities. The resultant aortic stiffness increase predominates much more in the central elastic arteries than in the distal arteries, and thus generates an increase in central pressure pulse. ${ }^{29)}$ Because of these physiological and pathological PP amplifications between central and peripheral arteries, ${ }^{30-32)}$ brachial PP, used in the aortic stiffness index formula, may not reflect aortic PP. Additionally, it is an important limitation that the times of the measurements of blood pressure and echocardiography are not simultaneous. Therefore, we believe that an aortic stiffness index calculated through this formula in which brachial PP is used will not really reflect aortic stiffness.

Direct measurements of stiffness may be of greater help than the other methods. In the aorta, the ejection of blood dilates the aortic wall and generates a pressure wave. Modification of the distension pressure within the artery causes an identical modification of the arterial diameter. The large elastic arteries will present a greater modification of their diameter than the small muscular arteries. ${ }^{33,34)}$ Since such diameter changes primarily relate to the wall movements, they can be studied easily and directly with CDTI. These resultant measurements, however, can directly and qualitatively indicate the changes in stiffness and distensibility. Its advantage is that, as a measurement technique, it is not as affected by hematological and cardiovascular physiology as are the other two techniques.

Wall movements in the aorta are synchronous but reverse with the heart, ie. while the ventricle contracts, the aorta expands, and while the ventricle relaxes, the aorta contracts. ${ }^{34)}$ The wave profile is shaped just as in the ventricle depending on the wall movements parallel to the pressure changes in the lumen; in other words, aortic S obtained during ventricular systole, and aortic $\mathrm{E}$ and A during diastole. Therefore, arteriosclerosis will cause the aortic wall to expand less during ventricular systole, and this will present itself as a decrease in the aortic $\mathrm{S}$ velocity. In our study population, aortic $\mathrm{S}$ velocity showed intra- and inter- 
observer agreement and reproducibility, and it was found to be reduced in the group with $\mathrm{CAD}$; however, there was no significant difference between aortic $\mathrm{E}$ and A velocity.

The elastic properties and wall movements of the aorta can be affected by risk factors for $\mathrm{CAD}$, such as hypercholesterolemia, hypertension, diabetes mellitus, sex, age, and smoking habit. ${ }^{11,15-17,35-37)}$ Of these CAD risk factors, sex and the number of patients with hypertension and smoking habit were different between our groups. However, the findings were tested after adjustment for all CAD risk factors, considering their possible effects. In conclusion, the level of significance did not change, indicating that our results occurred independently of these risk factors.

Examination of the elastic structure of the aorta through the wall movements with CDTI is a practical approach. Nevertheless, some questions may be raised at this point. First, can the amplitude of the movement in the aorta produce the Doppler signals we have taken, or do these signals occur depending on the systolic and diastolic movements of the heart? The low level of velocities in the upper aortic wall in comparison with those in the mitral annulus, and detection of no correlation between the aortic $\mathrm{S}$ and annulus $\mathrm{S}$ velocities seem to suggest the velocities we have measured in the aorta stem from arterial wall movements. However, despite everything, if the ventricular movement has an effect, this effect should be expected to disappear with the adjustment according to the functions of the ventricle. Secondly, do the aortic CDTI measurements really indicate changes in the elastic properties of the aorta? For this purpose, aortic stiffness and distensibility were studied with a method accepted in the literature ${ }^{11)}$ and their relationship with the direct measurements made by CTDI. In our study, the aortic stiffness was increased, and the aortic S, E and A velocities were decreased in the group with CAD. Nevertheless, of the aortic CDTI measurements, only the decrease in aortic $\mathrm{S}$ velocity reached statistical significance, and this showed a negative correlation $(r=-0.28)$ with the rise in stiffness and a positive correlation with distensibility. In conclusion, these findings suggest that aortic $\mathrm{S}$ velocity is correlated with aortic stiffness and distensibility, and that the elastic properties of the aorta can be also evaluated with CDTI. The low correlation coefficient between the aortic stiffness index and aortic $\mathrm{S}$ velocity can be explained by the possibility that the aortic stiffness index, computed using a formula, does not reflect the level of stiffness in reality.

Increased arterial stiffness may increase CAD because of an elevation of systolic blood pressure, which raises left ventricular afterload, and because of a decrease in diastolic blood pressure, which alters coronary perfusion. ${ }^{10)}$ While aortic stiffness is a risk factor for recurrent acute coronary events in symptomatic patients with ischemic heart disease, ${ }^{4)}$ it does not predict the presence of coronary 
and extracoronary arteriosclerosis in asymptomatic subjects at risk for cardiovascular disease. ${ }^{38)}$ In our study population, aortic S velocity was significantly lower in the group with CAD and was associated with the rise in stiffness. It is clear that this difference has a predictive potential, and it has been observed that the risk of $\mathrm{CAD}$ was 3.6 times greater in patients with aortic $\mathrm{S}$ velocity below $0.06 \mathrm{~m} / \mathrm{sec}$, and 1.4 times greater in patients with increased aortic stiffness.

In conclusion, elastic properties of the aorta can be directly assessed reproducibly by measuring the movements in the upper wall of the aorta by CDTI. It was observed that reduced aortic $\mathrm{S}$ velocity is associated with increased aortic stiffness. Reduced aortic S velocity and increased aortic stiffness are important predictors of CAD. However, we believe that our preliminary findings need to be confirmed by a larger controlled and randomized series of studies.

\section{REFERENCES}

1. Mathur KS, Kashyap SK, Kumar V. Correlation of the extent and severity of atherosclerosis in the coronary and cerebral arteries. Circulation 1963; 27: 929-34.

2. van Popele NM, Grobbee DE, Bots ML. Association between arterial stiffness and atherosclerosis: the Rotterdam Study. Stroke 2001; 32: 454-60.

3. Stefanadis C, Wooley CF, Bush CA, Kolibash AJ, Boudoulas H. Aortic distensibility abnormalities in coronary artery disease. Am J Cardiol 1987; 59: 1300-4.

4. Stefanadis C, Dernellis J, Tsiamis E, Stratos C, Diamantopoulos L, Michaelides A, et al. Aortic stiffness as a risk factor for recurrent acute coronary events in patients with ischemic heart disease. Eur Heart J 2000; 21 : 390-6.

5. Hirai T, Sasayama S, Kawasaki T, Yagi SI. Stiffness of systemic arteries in patients with myocardial infarction. A noninvasive method to predict severity of coronary atherosclerosis. Circulation 1989; 80: 78-86.

6. Bramwell JC, Hill AV. Velocity of transmission of the pulse wave and elasticity of arteries. Lancet 1922; 1: 8912.

7. Lang RM, Cholley BP, Korcarz C, Marcus RH, Shroff SG. Measurement of regional elastic properties of the human aorta. A new application of transesophageal echocardiography with automated border detection and calibrated subclavian pulse tracings. Circulation 1994; 90: 1875-82.

8. Stefanadis C, Stratos C, Vlachopoulos C, et al. Pressure-diameter relation of the human aorta. A new method of determination by the application of a special ultrasonic dimension catheter. Circulation 1995; 92: 2210-9.

9. Asmar R, Benetos A, Topouchian J, Laurent P, Panier B, Brisac AM, et al. Assessment of arterial distensibility by automatic pulse wave velocity measurement. Validation and clinical application studies. Hypertension 1995; 26: 485-90.

10. Laurent S, Boutouyrie P, Asmar R, Gautier I, Laloux B, Guize L, et al. Aortic stiffness is an independent predictor of all-cause and cardiovascular mortality in hypertensive patients. Hypertension 2001; 37: 1236-41.

11. Pitsavos C, Toutouzas K, Dernellis J, Skoumas J, Skoumbourdis E, Stefanadis C, et al. Aortic stiffness in young patients with heterozygous familial hypercholesterolemia. Am Heart J 1998; 135: 604-8.

12. Wilkenshoff UM, Sovany A, Wingström L, et al. Regional mean systolic velocity estimation by real time color Doppler imaging: A new technique for quantifying regional systolic function. J Am Soc Echocardiogr 1998; 11: 683-92.

13. Sutherland GR, Fleming A, McDicken WN, et al. Does Doppler myocardial imaging give new insight or simply old information revisited? Heart 1996; 76: 197-9.

14. Hirai T, Sasayama, Kawasaki T, Yagi S. Stiffness of systemic arteries in patients with myocardial infarction. A noninvasive method to predict severity of coronary atherosclerosis. Circulation 1989; 80: 78-86. 
15. Learoyd BM, Taylor MG. Alterations with age in the viscoelastic properties of human arterial walls. Circ Res 1966; 18: 278-92.

16. Stefanadis C, Dernellis J, Vlachopoulos C, Tsioufis C, Tsiamis E, Toutouzas K, et al. Aortic function in arterial hypertension determined by pressure-diameter relation effects of diltiazem. Circulation 1997; 96: 1853-8.

17. Lehmann ED, Gosling RG, Sönksen PH. Arterial wall compliance in diabetes. Diabet Med 1992; 9: 114-9.

18. Stefanadis C, Tsiamis E, Vlachopoulos C, Stratos C, Toutouzas K, Pitsavos C, et al. Unfavorable effect of smoking on the elastic properties of the human aorta. Circulation 1997; 95: 31-8.

19. Wilmer W. Nichols. McDonald's blood flow in arteries: theoretic, experimental and clinical principles. London: Arnold, 1998; 216-69.

20. Laogun AA, Gosling RG. In vivo arterial compliance in man. Clin Phys Physiol Meas 1982; 3: 201-12.

21. Draaijer P, Kool MJ, Maessen JM, van Bortel LM, de Leuw PW, van Hoof JP, et al. Vascular distensibility and compliance in salt-sensitive and salt-resistant borderline hypertension. J Hypertens 1993; 11: 1199-207.

22. Klip W. Difficulties in the measurement of pulse-wave velocity. Am Heart J 1958; 6: 806-13.

23. Beyerholm O. Studies of the velocity of transmission of the pulse wave velocity in normal individuals. Acta Med Scand 1927; 67: 203-35.

24. Hickson SK, McSwiney BA. Effect of respiratory movements on PWV. J Physiol 1924; 59: 217.

25. Lantelme P, Milon H, Gharib C, Gayet C, Fortrat JO. White coat effect and reactivity to stress. Cardiovascular and autonomic nervous system responses. Hypertension 1998; 31: 1021-9.

26. Lehmann ED, Gosling RG, Sönksen PH. Arterial wall compliance in diabetes. Diabet Med 1992; 9: 114-9.

27. Lehmann ED, Watts GF, Fatemi-Langroudi B, Gosling RG. Aortic compliance in young patients with heterozygous familial hypercholesterolemia. Clin Sci 1992; 83: 717-21.

28. Hirai T, Sasayama S, Kawasaki T, Yagi SI. Stiffness of systemic arteries in patients with myocardial infarction. A non-invasive method to predict severity of coronary atherosclerosis. Circulation 1989; 80: 78-86.

29. Benetos A, Laurent S, Hoeks AP, Boutouyrie PH, Safar ME. Arterial alterations with ageing and high blood pressure: a non-invasive study of carotid and femoral arteries. Arterioscler Thromb 1993; 13: 90-7.

30. O'Rourke M, Frohlich ED. Pulse pressure: is it a clinically useful risk factor? Hypertension 1999; 34: 372-4.

31. Stergiopoulos N, Westerhof N. Determinants of pulse pressure. Hypertension 1998; 32: 556-9.

32. Jondeau G, Boutouyrie $\mathrm{P}$, et al. Central aortic pulse pressure is a major determinant of aortic dilatation in Marfan syndrome. Circulation. 1999; 99: 2677-81.

33. Safar M. Arteries in clinical hypertension. New York: Lippincott-Raven, 1996; 21-30.

34. Ganong WF. Review of Medical Physiology. San Francisco: Appleton\&Lange, 1987; 466-76.

35. Stratos C, Stefanadis C, Kallikazaros I, Boudoulas H, Toutouzas P. Ascending aorta distensibility abnormalities in hypertensive patients and response to nifedipine administration. Am J Med 1992; 93: 505-12.

36. Armentano RL, Barra JG, Levenson J, et al. Arterial wall mechanics in conscious dogs: assessment of viscous, inertial, and elastic moduli to characterize aortic wall behavior. Circ Res 1995; 76: 468-78.

37. Oxlund H, Rasmussen LM, Andreassen TT, Heickendorff L. Increased aortic stiffness in patients with type 1 (insulin-dependent) diabetes mellitus. Diabetologia 1989; 32: 748-58.

38. Magnien JL, Simon A, Denarie N, Del-Pino M, Gariepy J, Segond P, et al. Aortic stiffening does not predict coronary and extracoronary atherosclerosis in asymptomatic men at risk for cardiovascular disease. Am J Hypertents 1998; 11: 293-301. 